ORIGINAL RESEARCH PAPER

\title{
CENTRAL OBESITY AND BEER CONSUMPTION
}

\author{
CORINA-AURELIA ZUGRAVU ${ }^{1 *}$, DANIELA PATRASCU², MARINA OTELEA ${ }^{3}$ \\ Department of Hygiene and Ecology, Faculty of Nursing and Mifwifery, University of Medicine \\ and Pharmacy Carol Davila, Romania \\ Department of Hygiene and Ecology, Faculty of Medicine, University of Medicine and \\ Pharmacy Carol Davila, Romania \\ Department of Physiopathology, Faculty of Medicine, University of Medicine and Pharmacy \\ Carol Davila, Romania, \\ *Corresponding author: corina.zugravu@insp.gov.ro
}

Received on $13^{\text {th }}$ August 2019

Revised on $19^{\text {th }}$ November 2019

Central obesity is the accumulation of fat in the abdominal region, and is a marker for Metabolic Syndrome. Since beer is a popular drink in Romania, we searched for eventual connection between beer consumption and waist circumference (WC). We carried out a transversal semi-quantitative study targeting the adult population of Romania. The relations between WC, WHR (waist hip ratio) and beer consumption were variable and non-linear. Regressions for WC and WHR did not bring statistically significant coefficients, showing that there is no significant link between beer consumption and WC or WHR. We could conclude that beer ingestion by itself is not associated with a higher prevalence of abdominal obesity.

Keywords: beer, central obesity, body mass index, waist circumference, waist hip ratio

\section{Introduction}

Obesity is a central theme of our modern society. Its consequences go far beyond psychosocial effects, taking their tall both on humans ' health and on public health expenses all around the Globe. The central type of obesity consists in the accumulation of fat in the abdominal region, between viscera residing in this area, and is considered as a marker for the Metabolic Syndrome, linking the abdominal obesity per se, independent of the Body Mass Index (BMI), with cardio vascular disease (Yoo et al., 2017), diabetes, several neoplasia, inflammatory diseases, and even with a lower brain volume in middle aged adults (Debette et al., 2010). These findings were confirmed by the results of the Emerging Risk Factors Collaboration

https://doi.org/10.35219/foodtechnology.2019.2.08 
(Tcernof et al., 2013) and by the inclusion of this anthropometric marker as one of the criteria of the metabolic syndrome.

Practice has shown that for similar BMI people might have very different waist circumferences. As a consequence, the circumference itself can be an independent risk factor for non-communicable diseases (Owolabi et al., 2017).

Visceral obesity was found as being closely related to clustering cardio metabolic risk factors like hypertriglyceridemia; increased synthesis and secretion of VLDL (very low density lipids) in liver; reduced clearance of triglyceride-rich lipoproteins; presence of small, dense LDL (low density lipids) particles; and low HDL (high density lipids) cholesterol levels, high free fatty acid availability (Tchernof et al., 2013); the release of pro inflammatory cytokines from the adipose tissue; liver insulin resistance and inflammation (Yung et al., 2014).

Besides waist circumference, another parameter, the waist/hip ratio, has also been found to be a risk factor for some chronic diseases, like cardio vascular ones. The waist hip ratio is also a good indicator for abdominal android adiposity (Mathieu et al., 2009). Even more, studies have shown that a normal BMI associated with an obese value for Waist Hip Ratio (WHR) is a predictor for a higher mortality than BMI-defined obesity, especially in the absence of a central fat distribution (Sahakyan et al., 2015). The distribution of fat and its accumulation in the abdominal cavity is determined by many factors, among which some are little or no susceptible to change (age, gender, heredity, etc.). On the contrary, diet is the modifiable factor for this type of obesity.

Until now, there is no consensus regarding the relation between the increased body weight and moderate alcohol intake, especially originating from beer. Beer is widely popular, so its impact on health can be considered of a greater concern than of other alcoholic beverages. Because of the higher content of carbohydrates per unit of ethanol than wines or some spirits, it was supposed that beer increases the risk of obesity much more than other alcoholic beverages. Popular culture has linked beer consumption with a greater girth. Beer became the so called determinant of the "beer belly", even though the caloric balance of the beer drinkers was frequently positive just because the over consumption of highly caloric food and lack of physical exercise. Phytoestrogens from hops have been blamed for "bear gut" in pop literature, but there is no research to confirm the hypothesis. A simple search on Google for "beer" and "belly" brings over 16000 000 results, most of them offering swift "cures" for the problem.

As many other countries, Romania is confronted with an explosion of obesity and health related issues, with $23,1 \%$ of adults obese, figures growing steadily with age (9.9\% in adults up to 39 years, versus $41.6 \%$ in people over 60 ) (Roman et al., 2015) Since beer is a very popular drink in Romania, which is the $7^{\text {th }}$ beer consumer in Europe, in the present study we searched for eventual connection between beer consumption and abdominal circumference, as well as for eventual links between beer consumption and other somatic parameters that have been described in literature as risk factors for metabolic disturbances (the waist hip ratio). 


\section{Materials and methods}

A transversal semi-quantitative study targeting the adult population of Romania was conducted between March and April 2014, as part of a larger frame of evaluation of food intake in Romania and of monitoring of certain parameters linked with obesity. Gathering of data was carried out by field investigators trained by staff specialized in public health nutrition. Sampling was based on a stratified multistage cluster design that comprised allocating for geographical area, settlement, age and gender. The official census data was provided by the National Institute of Statistics. Exclusion criteria were dieting for medical reasons. Selfimposed diets based on personal beliefs (vegetarian, vegan, raw, religious, etc) were not considered a reason for exclusion. Of the 1520 initially selected subjects, 13 failed to complete the study, so a total number of 1507 subjects completed the study, 723 men and 784 women, all aged 18 or above.

Face-to-face interviews were conducted by trained field operators in respondents' homes. A questionnaire tool and direct anthropometric measurements were employed for data collection. The questionnaire format allowed for assembling of dietary, physical activity, anthropometric, smoking, demographic and social grade data. Training of interviewers included lectures and practice sessions, as well as printed hand-outs. Each respondent was asked to sign an informed consent.

\section{The questionnaire}

Habitual food and beverages intake was assessed by considering the frequency by which food items or specific food groups were consumed over a reference period of one year. The EPIC-Norfolk food frequency questionnaire was adjusted into 110 items and validated against prospective food intake data (from the Romanian National Institute of Statistics' household budget survey). The original EPICNorfolk questionnaire is a food frequency questionnaire, which was first developed in the year 1988 and was made up by a food list and portion sizes likely to be consumed by an adult population.

Data regarding beer consumption was quantified into a special variable with the following values: $0=$ no or very low consumption (less than a portion per week); 1 $=$ low consumption (maximum 4 portions per week, for women and maximum 6 , per men); 2 moderate consumption (5-7 portion per week for women and 1-2 portions per day, for men); $3=$ excessive consumption (more than one portion per day for women and more than 2 for men). One portion was considered as being equivalent to a can $(330 \mathrm{ml})$ of beer with $4.5 \%$ alcohol, as stated in the Guide for a Healthy Diet of the Romanian Nutrition Society (Romanian Society for Nutrition, 2017).

Data for physical activity was scored based on frequency of light, moderate and vigorous activities, considering the same reference period. Moderate to vigorous activity was considered when respondents reported having a higher cardiac rhythm while carrying it out, in accordance with the WHO definition (WHO, 2017). Since the last class, vigorous activity, was reported in less the $2 \%$ of the respondents, moderate and vigorous groups were merged into one category (moderate to 
vigorous). Social grade was calculated as an index correlating place of work with education, and higher values show a higher social grade.

\section{Somatic parameters}

Self-reported values for height and weight were gathered to calculate the bodymass index (BMI). Waist circumference (WC) and hip circumference (HC) were measured by interviewers and recorded in centimetres upon direct measurements with a tape over minimal clothing. WC was determined midway between the top of the iliac crest and the lowest rib. $\mathrm{HC}$ was measured at the level of the greatest protrusion of the gluteal muscles. BMI was considered normal for values between 18.5 and 24.9; as for abdominal circumference and waist hip ratio, values considered as normal for Caucasians by the WHO (WHO, 2011) were taken into consideration (man $<94 \mathrm{~cm}$, woman $<80 \mathrm{~cm}$ for the abdominal circumference, respectively man $<0.9$, woman $<0.85$ for waist hip ratio). Depending on somatic data and in order to facilitate analysis, the participants were divided in 4 classes of BMI ( underweight $=0$, normally weighted $=1$, overweight $=3$ and obese $=4$ ).

\section{Statistical analysis}

Statistics were carried out with SPSS 13.0 software. Somatic and socio demographic parameters had a normal distribution at the Kolmogorov-Smirnov test, so parametric tests could be applied. The statistical significance threshold (p) has been considered at 0.05 . Descriptive, correlation, 2 step Cluster Analysis and Tree Classification tests were applied for different variables. Beer consumption categories were considered in correlation with demographics, smoking, somatic indexes, food consumption patterns and physical activity and only those variables significantly correlated were taken into consideration as variables in regressions. For both somatic variables distinctive for central obesity (WC and WHR) and separately for women and men, linear (or binary) regressions have been carried out, with different covariates.

\section{Results and discussion}

Somatic parameters values, on gender and age are figured in Table 1.

Table 1. Somatic parameters: medium values (with SD), maximum and minimum values in the sample

\begin{tabular}{llcccc}
\hline Gender & Values & $\begin{array}{c}\text { BMI } \\
\left(\mathbf{k g} / \mathbf{m}^{\mathbf{2}}\right)\end{array}$ & WC (cm) & HC (cm) & WHR \\
\hline Men & Mean & 26.20 & 94.5 & 102.0 & 0.90 \\
& SD & 4.10 & 14.7 & 13.2 & 0.10 \\
& Minimum & 16.10 & 50.0 & 53.0 & 0.60 \\
& Maximum & 44.60 & 136.0 & 150 & 1.40 \\
\hline Women & Mean & 24.80 & 85.0 & 100.4 & 0.85 \\
& SD & 5.00 & 16.7 & 14.3 & 0.11 \\
& Minimum & 15.25 & 52.0 & 60.0 & 0.53 \\
& Maximum & 59.00 & 135.0 & 149.0 & 1.33 \\
\hline
\end{tabular}


Men presented higher BMI than women, with a mean value in the range of overweight. Average WC is, for women, above the normal cut off value, while average WHR is, for both genders, exactly at the cut of value. Data allows no definitive conclusions, since age influences strongly somatic parameters in both sexes, especially WC and WHR for women (Figures 1-4 and Table 2).

On BMI classes, our study produced figures similar to other research carried out in recent years in Romania (Roman et al., 2015).

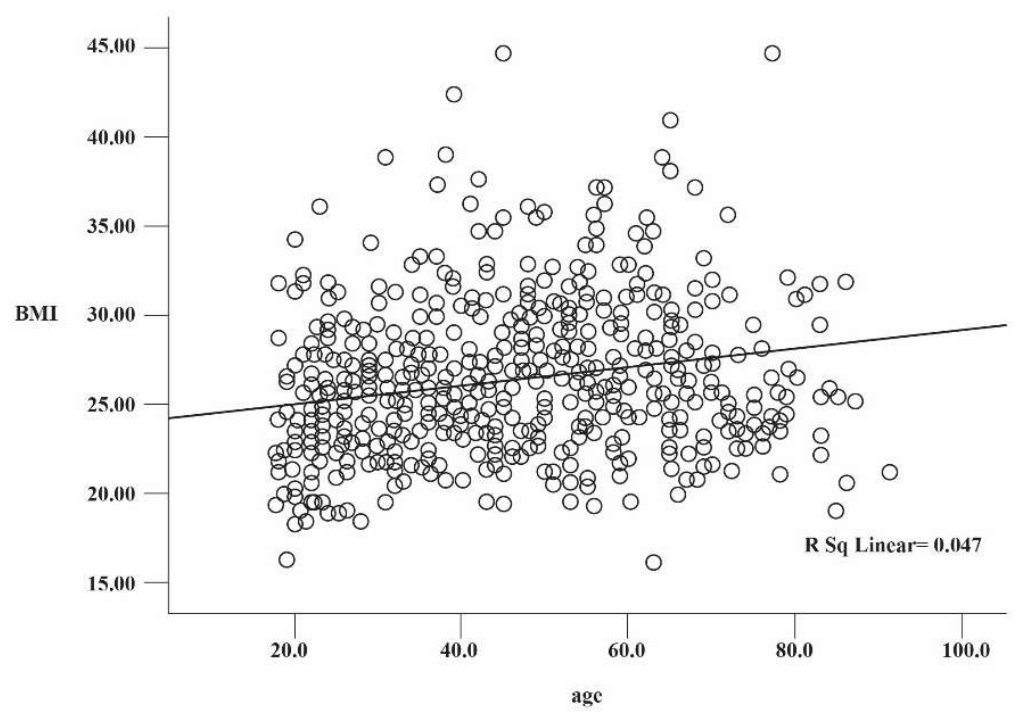

Figure 1. BMI distribution on ages in men

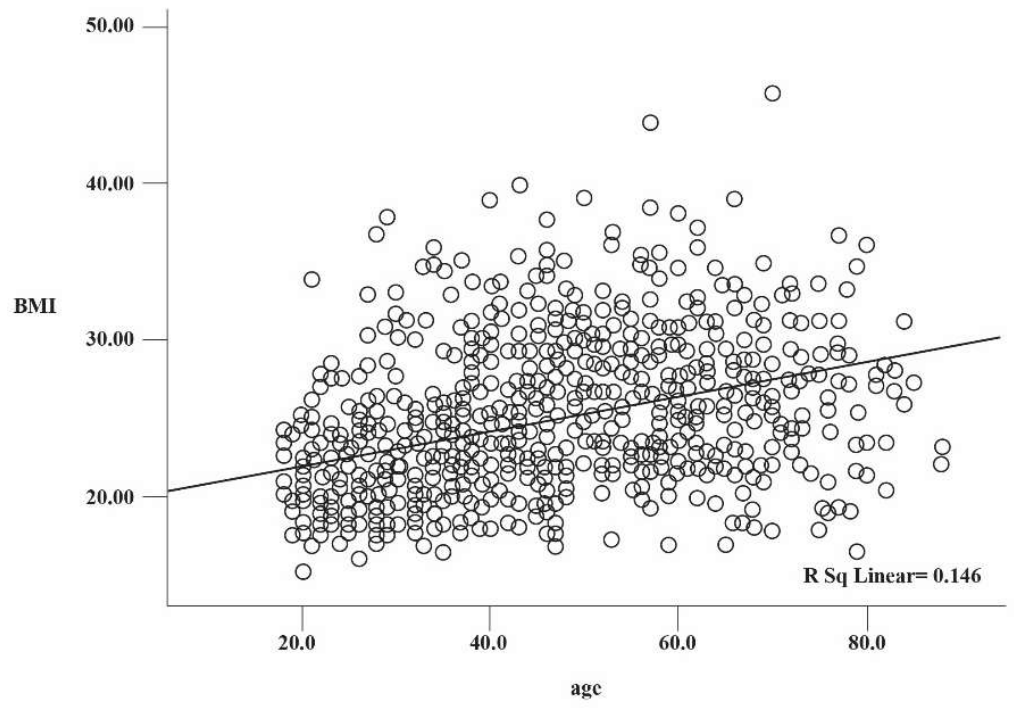

Figure 2. BMI distribution on ages in women 

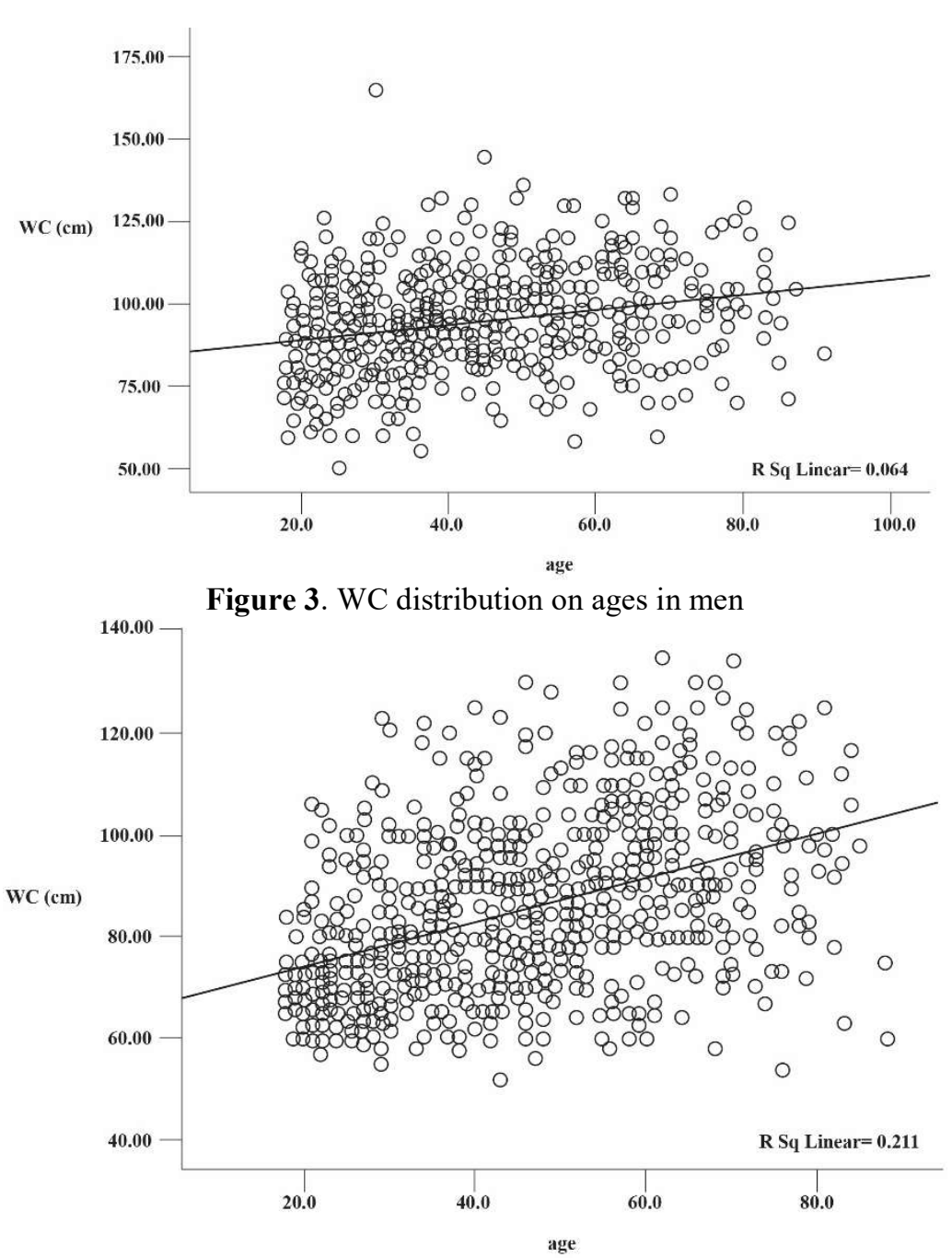

Figure 4. WC distribution on ages in women

Table 2. BMI classes in the sample

\begin{tabular}{lcc}
\hline Gender & BMI Class & Percent $(\%)$ \\
\hline men & 1 & 0.5 \\
& 2 & 40.0 \\
3 & 40.5 \\
& 4 & 19.0 \\
\multirow{3}{*}{ women } & 1 & 6.0 \\
& 2 & 48.0 \\
& 3 & 30.0 \\
& 4 & 16.0 \\
\hline
\end{tabular}

Where $1=$ underweight, $2=$ normally weighted; $3=$ overweight; $4=$ obese 
Beer consumption, by gender, is presented in table 3. The excessive consumption group in women had just one person, so it has been merged with the moderate group.

Table 3. Categories of beer consumption, on genders

\begin{tabular}{llr}
\hline Gender & $\begin{array}{l}\text { Frequency of } \\
\text { consumption }\end{array}$ & Percent (\%) \\
\hline men & No & 40.1 \\
& Low & 42.8 \\
& Moderate & 11.8 \\
\multirow{3}{*}{ women } & Excessive & 5.2 \\
& No & 81.2 \\
& Low & 10.7 \\
& Moderate & 6.7 \\
& Excessive & 0.07 \\
\hline
\end{tabular}

Men drink beer more frequently than women, which, as a whole, drink less alcoholic beverages. Alcoholic beverages are drunk in a mixed pattern. From the questionnaire, only $2.4 \%$ from the respondents declare exclusive beer consumption, $39 \%$ declare to drink only rarely alcoholic beverages, and the rest drink different alcoholic products, among which the most consumed is, however, beer.

In order to establish the type of alcoholic beverages consumed in the sample, a two-step cluster analysis has been carried out, having as continuous variables, the beer, wine, and spirit consumption, and as categorical, age and gender. Age had no statistical significance, and, by using the Bayesian Schwartz Criteria, three clusters were selected.

- the first cluster was entirely formed by women with a very low to no consumption of alcoholic beverages

- the next cluster was formed exclusively by men, consuming, in a descending order, beer, wine and spirits

- the last cluster was formed by both men and women (though more men) and the total consumption of alcoholic beverages was smaller than the one in the second cluster, types of beverages being the same

It has been concluded that there is not a significant group consuming exclusively beer, as in the Boback study (Boback et al., 2013), but that when drinking an alcoholic beverage, beer is the most common choice in Romania.

Though we searched for specific food intake characteristics for each group of beer consumption (by the Tree classification tool), no such patterns could be identified, all the groups having a heterogenous intake of more nutritious and less nutritious food groups (data not presented). There was no model of intake of high caloric food associated with beer consumption, like preferences for snacks or highly fatty meat. Thus, we could not infer that effects on somatic parameters were, in fact, caused by associated eating patterns. The same could be said about smoking, which did not correlate significantly neither with any of the somatic parameters, nor with 
beer consumption. WC and WHR, on beer consumption category and gender, are presented in the figures 5-8.

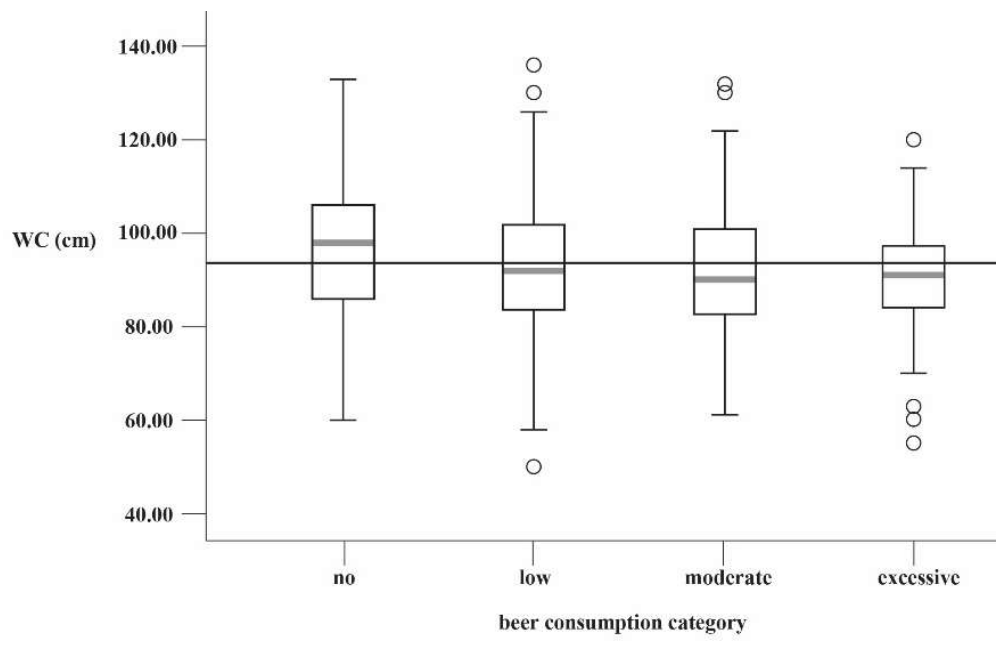

Figure 5. WC for men, on beer consumption category

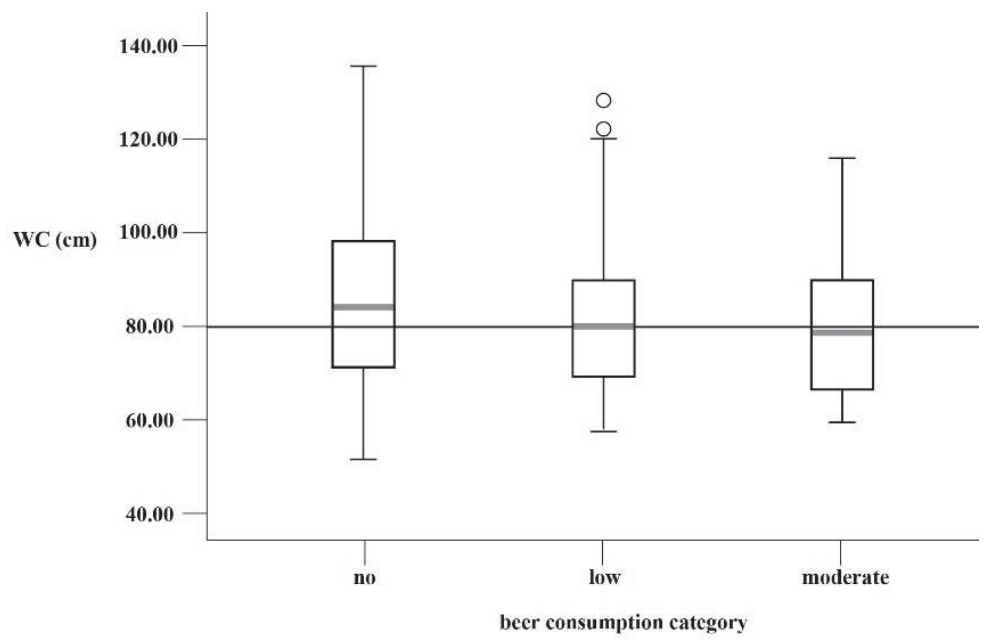

Figure 6. WC for women, on beer consumption category

The relations between WC, WHR and beer consumption are variable and nonlinear, generally with higher median values for non-consumers than for other categories of consumption. Low consumption gives values closest to the cut off value, in both parameters and genders, with the exception of WHR in women, where low consumption is significantly below the cut off value.

Linear regressions for WC and WHR were carried out, with categories of beer consumption as independent variables and with non consumers as reference 
category; in the first model we considered just one covariate, age, and in the following models (multivariate), age, social index, BMI (as continuous variable), physical activity. Even though in other studies smoking has been included in regressions, we found no significant correlation with beer drinking or any somatic parameter, so we did not include it in the present analysis.

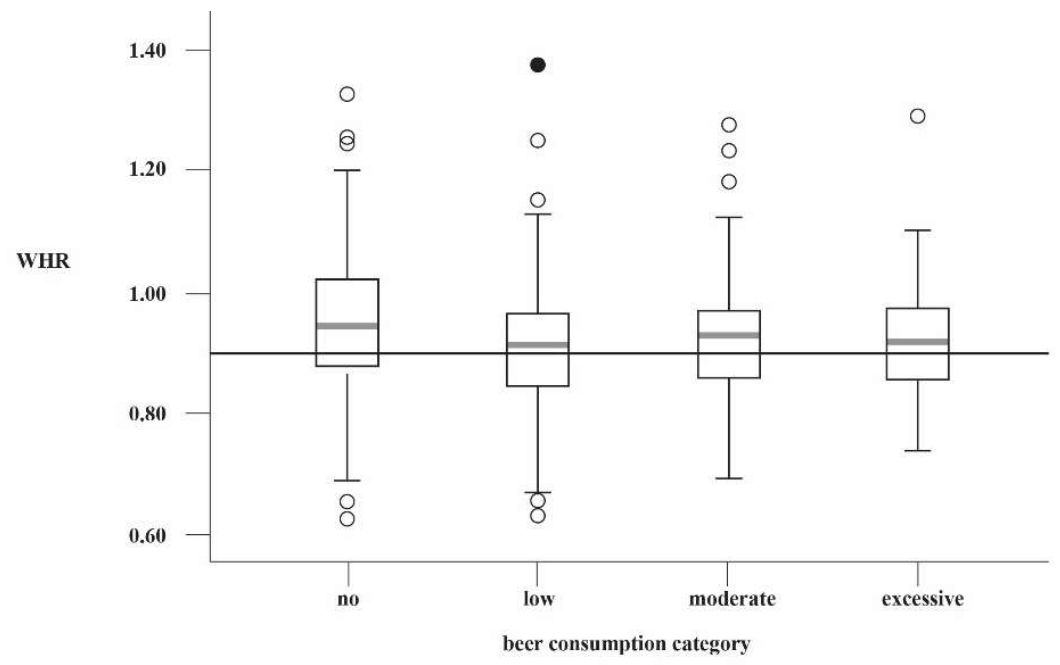

Figure 7. WHR for men, on beer consumption category

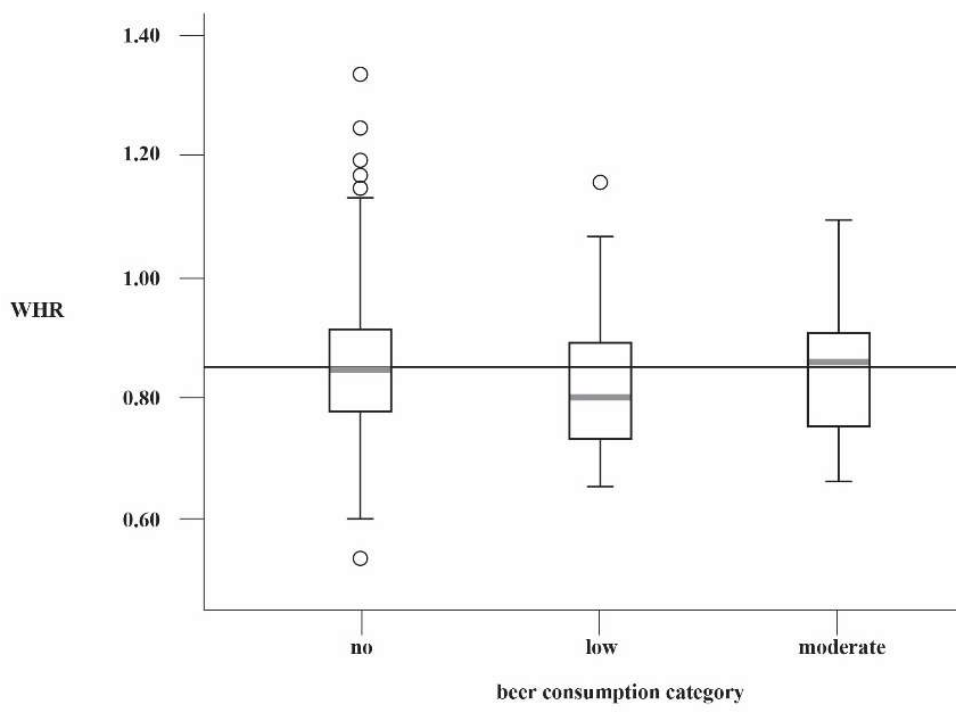

Figure 8. WHR for women, on beer consumption category

We also did not include consumption of other alcohol beverages, which, due to the Romanian mixed pattern of consumption (beer, as well as wine or spirits), would introduce multicollinearity in the models. BMI was considered as variable in 
regressions, both because it is a marker of total caloric intake and because it has a strong and independent influence on the WC. Regarding the WHR, both lean and obese individuals can end up having similar values, so the correction for the BMI was considered useful. Coefficients and their statistical significance are figured in table 4 .

Table 4. Regressions coefficients ( $\mathrm{B}$ and beta) and their significance in age adjusted and multivariate adjusted models, for groups of beer consumption and somatic parameters of central obesity

\begin{tabular}{|c|c|c|c|c|c|c|c|c|}
\hline \multirow{3}{*}{$\begin{array}{l}\text { Frequency of } \\
\text { beer } \\
\text { consumption }\end{array}$} & \multicolumn{4}{|c|}{ WC } & \multicolumn{4}{|c|}{ WHR } \\
\hline & \multicolumn{2}{|c|}{ Age adjusted } & \multicolumn{2}{|c|}{ Multivariate } & \multicolumn{2}{|c|}{ Age adjusted } & \multicolumn{2}{|c|}{ Multivariate } \\
\hline & B & beta & $\mathrm{B}$ & beta & B & beta & $\mathrm{B}$ & beta \\
\hline \multicolumn{9}{|l|}{ Men } \\
\hline $\begin{array}{c}\text { No beer } \\
\text { consumption }\end{array}$ & \multicolumn{8}{|c|}{ Reference category } \\
\hline $\begin{array}{l}\text { Low beer } \\
\text { consumption }\end{array}$ & -0.623 & -0.021 & 0.716 & 0.024 & -0.023 & -0.106 & -0.015 & -0.069 \\
\hline $\begin{array}{l}\text { Moderate beer } \\
\text { consumption }\end{array}$ & -1.528 & -0.033 & 1.234 & 0.026 & 0.002 & 0.005 & 0.020 & 0.058 \\
\hline $\begin{array}{c}\text { Excessive } \\
\text { beer } \\
\text { consumption }\end{array}$ & -3.132 & -0.048 & 0.422 & 0.007 & 0.005 & 0.011 & 0.015 & 0.032 \\
\hline \multicolumn{9}{|l|}{ Women } \\
\hline $\begin{array}{l}\text { No beer beer } \\
\text { consumption }\end{array}$ & \multicolumn{8}{|c|}{ Reference category } \\
\hline $\begin{array}{l}\text { Low beer beer } \\
\text { consumption }\end{array}$ & -2.013 & -0.037 & -0.950 & -0.02 & -0.018 & -0.051 & -0.017 & -0.047 \\
\hline $\begin{array}{c}\text { Moderate beer } \\
\text { beer } \\
\text { consumption }\end{array}$ & -4.772 & -0.072 & -0.002 & 0.00 & -0.003 & -0.007 & 0.013 & 0.028 \\
\hline
\end{tabular}

None of the values were statistically significant, showing that there is no significant link between beer consumption and WC or WHR. Even though nonsignificant, some coefficients show the inverse influence of beer consumption on circumferences. In the age-controlled group, the greatest influence on WC can be noticed in the moderate group for women and excessive group for men, but the influence drops in multivariate models, due to other variables, most likely physical activity. On WHR in age controlled regressions, the low consumption had the top influence, and the drop in influence in multivariate models was rather small so there might be some direct interaction involved.

In multivariate models, low beer consumption in women had a stronger and negative influence on somatic parameters, than a moderate one, compared to no beer consumption. In men the same effect was noticeable, with the strongest and negative effect of low consumption group on WHR.

Because BMI is a significant determinant for WC and WHR, we carried out a second round of regressions with the same covariates, but taking in consideration a categorical BMI (underweight, normal, overweight, obese). None of the beer consumption categories had statistically significant coefficients, with the exception 
of the group of obese men, where moderate beer consumption was associated with significantly greater chances to have a higher WC, compared with no beer consumption. (Beta $=0.251$, sig $=0.012$ ). This might be explained by particular elements of food behavior in obese men, which however could not be identified.

For obese men, we did not find an association between beer consumption and WC in the high alcohol consumption group. It seems, from these results, that the moderate consumption, when associated with excessive caloric intake, has the worst influence on WC.

Beer is one of the most consumed beverages all over the world and by far the most consumed alcoholic drink. While prepared by somewhat different recipes, beer has been used by humans since the dawn of civilization. Taking in account its widespread consumption, one has to consider the consequences on health. Studies have shown some health advantages of beer, especially on cardiovascular disease, most of them based on the low level of alcohol, but also on its phytonutrient content (Chiva-Blanch et al., 2013).

Weight and beer were generally not a topic for state of the art research, lay people assuming that beer is a cause for obesity, especially for the abdominal type whatever the level of consumption. However, beer is not a highly caloric beverage, its energy content being around the same as a soft drink or an orange juice (45 Kilocalories for a $4.5 \%$ alcoholic lager-type).

Our study is the only one following the connection between beer and the anthropometric measures in East Europe. Differences in somatic parameters were not statistically significant in relation to beer intake, though the smallest values for WHR were found for low consumers, both in men and women, and the highest values for WC in non-consumers. There was found no linear dose-related link between WC and WHR and beer consumption, neither in men, nor in women. The in-depth analysis by means of multivariate regression conforms what has been found in the descriptive analysis.

Some connections between lifelong alcohol consumption, weight and abdominal fat distribution have been noticed in large population studies (Bergman et al., 2011), but not in all (Tolstrup et al., 2005). Several factors could influence these findings, from a probably healthier lifestyle in low consumers, to fibbing for people declaring themselves as "non consumers". Alcohol is a beverage with calories and "liquid calories" contribute to long term weight gain, though some compensatory effect might be present (Butler et al., 2017). An attempt of quantitative stratification gave different results, as the criteria for group definition varied from one study to another. The increased risk of obesity of the non-drinkers was explained by other food intake behaviors: high caloric meals, food used for coping with mental distress, differences in sedentary activity (Rohrer et al., 2005). The number of no-drinkers was very low in our study, most probably because of no cultural or religious beliefs interference with alcohol consumption. In literature, more than four drinks/day (Breslow et al., 2005), five drinks/day in men (Butler et al., 2017) or lifelong average daily consumption of more than 6g/day (Bergman et al., 2011) were associated with an increase in BMI. 
Our results are comparable with other previous research. The smallest WC in the low and moderate range of alcohol consumption identified in our study population was also found by others (Tolstrup et al., 2005). The below cut-off values of WC, even adjusted to the BMI, in men with moderate or excessive consumption might not be a positive finding, but a first sign of malnutrition associated with the onset of alcoholism (Butler et al., 2017, Tolstrup et al., 2005). Overall, our results are corresponding to the $U$ shape relation that was found between alcohol intake, no matter what type (wine, beer or spirits) and metabolic components (Djoussee et al., 2004).

Concerning the targeted relation between beer and anthropometric measures, both convergent and divergent results with our study were reported. Similar to our figures, mild to moderate consumption of beer had favorable influence on WC (Freiberg et al., 2004), on other metabolic syndrome components, such as lipid profile and fasting insulin (Freiberg et al., 2004) and on BMI (Breslow et al., 2005). Consumption of more than 21 beers/week for men and 14 beers/week for women was found as risk for an increase WC in a large prospective Danish study (Vadstrup, 2003), but a 8.5 years prospective study of the EPIC cohort showed that the beer consumption odds ratio for WC increase is mostly explained by change in BMI (Schutze et al., 2009). In the same cohort, alcohol from beer showed higher risk than expected from BMI increase when average lifelong consumption was the risk factor considered in the analysis (Bergmann et al., 2011). In our study, the BMI did not influence the relation between beer consumption and WC, except in the obese men with moderate consumption. The influence was not reproduced in the high beer intake group, with lower, although non-significant WC than in the moderate consumption group. Less non-alcoholic energy food consumed by heavy drinkers was found by others (Butler et al., 2017). In line with these divergent results, a recent meta-analysis concluded that there is no scientific data consistently connecting the moderate beer ingestion with obesity, both general and abdominal (Bendsen et al., 2013).

Another characteristic of our study is the gender related behavior regarding beer consumption in our population, which was not specifically reported in the above mentioned studies. However, even if drinking less alcohol than men, women would choose beer over other alternatives. This is quite surprising, as gender difference in the pattern of alcohol preferences seems to be characteristic in cultures from all around the world, where beer is largely preferred by men (Fiala et al., 2013). Different consequences of beer consumption on somatic parameters, by gender, were described in different studies, where beer was positively associated with WHR in men, and it was weakly negatively related to BMI in women (Bobak et al., 2003). In a 5 years follow up cohort, each additional drink/day of alcohol decreases the body weight and $\mathrm{WC}$ among men and increases the $\mathrm{WC}_{\mathrm{BMI}}$ (WC adjusted for given BMI) among women. (Rohde et al., 2017).

Regarding beer influence on WC, we did not find an experimental proof for a presumed direct effect of beer consumption on abdominal obesity. It was highlighted that beer drinkers have generally less healthy diets. (Sluik et al., 2016). 
We did not find this association in our population and it might explain the differences between our study and those that connected WC increase with beer consumption. On the other hand, beer is considered an appetite stimulator, due to carbon dioxide and hops' bitter components. However, the ability of alcohol as an appetizer in beer was less than one of the equivalent amount of alcohol in a sparkling juice drink (Yeomans, 2010). Even more, hops might interfere by influencing fat deposits. A recent, 12 weeks, randomized, double blind, placebocontrolled study with mature extract hop found a significant reduction in the visceral fat area and in the total fat area (Morimoto-Kobayashi et al., 2016).

We concluded that the probability of beer ingestion being a determinant of higher WC and WHR in a population in which beer is the mostly consumed alcoholic beverage, but drunk along with other alcoholic beverages, is not significant. Somatic parameters and ponderal status are influenced by a multitude of elements, some modifiable (lifestyle), other not (age, gender, genetics), while beer is just a component of diet that cannot be considered in isolation as a cause for abdominal obesity, in low and moderate consumption.

\section{Limitations}

The pattern of drinking has been shown to have a big influence on human metabolism and we can infer, on weight. However, findings were generally inconclusive and contradictory and our study did not include data regarding these aspects.

We could not separate exclusive beer drinkers from the rest of alcohol consumers, cluster analysis showing the mixed drink pattern in the sample, so some of the results might be biased by alcohol consumption from different sources and its consequences on somatic parameters. In this respect, our study is relevant only for populations with combined alcohol consumption not for those where beer consumption is exclusive.

We carried out a transversal study, which could not evaluate the dynamic of beer consumption on long periods of time (years, decades). We did our best to reduce the general disadvantages of a cross sectional study. The questionnaire referred to habits covering a year, so occasional binge or exceptional consumption on short periods of time could not interfere with the final results. Again, being a cross sectional study implies no relation of causality could be obtained.

An element of error frequently encountered in inquiries regarding alcohol consumption is fibbing, many respondents minimizing their alcohol consumption through time. We can reckon that our study could not avoid this bias. However, beer is a low alcoholic beverage and seems to be less associated with inebriation or stigma in the lay people's opinion - in Romania, similar with Czeck Republic (Bobak et al., 2013), so we hope that respondents reported quantities and frequencies closer to real consumption. We have to notice, though, that in Romania beer is consumed not only during meals, but also on different social occasions (especially by men), when binging has a high probability. 


\section{Conclusions}

We can conclude that beer ingestion is not associated with a greater prevalence of abdominal (central) obesity. Somatic parameters describing central obesity are influenced by a multitude of factors, beer being not a major culprit but just one of the contributors of the total caloric intake. "Beer belly" might be just one of the many "nutritional myths" used to justify a certain lifestyle and its consequences on body parameters.

\section{Conflict of interest}

The study did benefit of funding from a private entity. However, there were no interferences in any step of the research or in drawing its conclusions. Data gathering was financed by a private grant from the Center of Studies on Beer, Health and Nutrition, Bucharest, Romania.

\section{References}

Bendsen, N.T., Christensen, R., Bartels, E.M., Kok, F.J., Sierksma, A., Raben, A., Astrup, A. 2013. Is beer consumption related to measures of abdominal and general obesity? A systematic review and meta-analysis. Nutition Reviews, 71(2), 67-87.

Bergmann, M.M., Schutze, M., Steffen, A. 2011. The association of lifetime alcohol use with measures of abdominal and general adiposity in a large-scale European cohort. European Journal of Clinical Nutrition, 65, 1079-1087

Bobak, M., Skodova, Z., Marmot, M. 2003. Beer and obesity: a cross-sectional study. European Journal of Clinical Nutrition, 57(10), 1250-1253

Breslow, R.A., Smothers, B.A. 2005. Drinking Patterns and Body Mass Index in Never Smokers: National Health Interview Survey, 1997-2001, American Journal of Epidemiology, 161, 368-376

Butler,L., Popkin, B.M., Poti, J.M. 2017. Associations of Alcoholic Beverage Consumption with Dietary Intake, Waist Circumference, and Body Mass Index in US Adults: National Health and Nutrition Examination Survey 2003-2012, Journal of the Academy of Nutrition and Dietetics, 17, 31621-31628. [Epub ahead of print]

Chiva-Blanch, G., Arranz, S., Lamuela-Raventos, R.M., Estruch, R. 2013. Effects of wine, alcohol and polyphenols on cardiovascular disease risk factors: evidences from human studies. Alcohol., 48(3), 270-277

Debette, S., Beiser, A., Hoffmann, U., Decarli, C., O'Donnell, C.J., Massaro, J.M. 2010. Visceral fat is associated with lower brain volume in healthy middle-aged adults. Annals of Neurology, 68,136-144.

Djoussé, L., Arnett, D. K., Eckfeldt, J. H., Province, M. A., Singer, M. R. Ellison, R. C. 2004. Alcohol Consumption and Metabolic Syndrome: Does the Type of Beverage Matter?. Obeesity Resources, 12, 1375-1385.

Freiberg, M.S., Cabral, H.J., Heeren, T.C., Vasan, R.S., Curtis-Ellison R. 2004. Alcohol Consumption and the Prevalence of the Metabolic Syndrome in the U.S. Diabetes Care.,27, 2954-2959

Fiala, J., Sochor, O., Klimusová, H., Homolka, M. 2017. Alcohol Consumption in Population Aged 25-65 Years Living in the Metropolis of South Moravia, Czech Republic. Central European Journal of Public Health, 25, 191-199.

Jung, U., Choi, M-S. 2014.Obesity and Its Metabolic Complications: The Role of Adipokines and the Relationship between Obesity, Inflammation, Insulin Resistance, Dyslipidemia and 
Nonalcoholic Fatty Liver Disease. International Journal of Molecular Science, 15, 6184 6223.

Mathieu, P., Poirier, P. Pibarot, P., Lemieux, I., Després, J.P. 2009. Visceral obesity: the link among inflammation, hypertension, and cardiovascular disease. Hypertension, 53, 577-584.

Morimoto-Kobayashi, Y., Ohara, K., Ashigai, H. 2016. Matured hop extract reduces body fat in healthy overweight humans: a randomized, double-blind, placebo-controlled parallel group study. Nutrtion Journal., 15, 25.

Owolabi, E.O., Ter, K, Goon, D., Adeniyi, O.V. 2017. Central obesity and normal-weight central obesity among adults attending healthcare facilities in Buffalo City Metropolitan Municipality, South Africa: a cross-sectional study. Journal of Health, Population and Nutrition, 36, 54.

Rohde, J., Angquist, L., Larsen, S.C. 2017. Alcohol consumption and its interaction with adiposity-associated genetic variants in relation to subsequent changes in waist circumference and body weight. Nutrition Journal, 16, 51 .

Rohrer, J.E., Rohland, B.M., Denison, A., Way, A. 2005. Frequency of alcohol use and obesity in community medicine patients. BMC Family Practice; 6, 17.

Romanian Society for Nutrition . Guide for a healthy diet ("Ghid pentru alimentatia sanatoasa"), p.147, available at: http://old.ms.ro/documente/Ghid1_8318_6022.pdf, accessed 30.04.2017

Roman, G., Bala, C., Creteanu, G., Graur, M., Morosanu, M,, Amorin, P. 2015. Obesity and Health-Related Lifestyle Factors in the General Population in Romania: a Cross Sectional Study. Acta Endocrinologica (Bucharest), 11, 64-72.

Sahakyan, K.R., Somers, V.K., Rodriguez-Escudero, J.P., Hodge, D.O., Carter R.E., Sochor, O. 2015. Normal-Weight Central Obesity: Implications for total and cardiovascular mortality. Annals Internal Medicine, 163, 827-835.

Schutze, M., Schulz, M., Steffen, A. 2009. Beer consumption and the 'beer belly': scientific basis or common belief? European Journal of Clinical Nutrition 63, 1143-1149

Sluik, D., Bezemer, R., Sierksma, A., Feskens, E. 2016. Alcoholic Beverage Preference and Dietary Habits: A Systematic Literature Review, Critical Reviews in Food Science and Nutrition, 56, 2370-2382.

Tchernof,A., Despres, J-P. 2013. Pathophysiology of Human Visceral Obesity: An Update . Physiological Rewievs, 93, 359-404.

Tolstrup, J.S., Heitmann, B.L., Tjønneland, A.M., Overvad, O.K., Sørensen, T.I.A., Grønbæk, M.N. 2005. The relation between drinking pattern and body mass index and waist and hip circumference. International Journal of Obesity, 29, 490-497

Vadstrup, E.S., Petersen, L., Sorensen, T.I.A., Gronbæk, M. 2003. Waist circumference in relation to history of amount and type of alcohol: results from the Copenhagen City Heart Study. InternationalJpurnal of Obesity Related Metabolic Disorders , 27, 238-246.

WHO. What is Moderate-intensity and Vigorous-intensity Physical Activity? Intensity of physical activity, available at http://www.who.int/dietphysicalactivity/physical activity_intensity/en/. accessed 1.05.2017

Yeomans, M.R. 2010. Short term effects of alcohol on appetite in humans. Effects of context and restrained eating. Appetite, 55, 565-573.

Yoo, B., Nam, H., Hwang, I.C., Park, Y. 2017. Correlation of cardiovascular risk factors with central obesity and multiple body mass index in Korea. Korean Journal of Family Medicine, 38, 338-345.

WHO .Waist Circumference and Waist-Hip Ratio: Report of a WHO expert consultation Geneva, 8-11 December 2008, available at http://whqlibdoc.who.int/publications/2011/9789241501491_eng.pdf, accessed 1.03.2017. 